\title{
Noticias breves
}

El día 17 de marzo, los estudiantes del ramo Filosofía Política de la Escuela de Filosofía de la UCSH, impartido por la Dra. Mariela Avila, tuvieron la visita del Dr. Patrice Vermeren. En esta ocasión, el Dr. Vermeren, ex-director del departamento de Filosofía de la Universidad París 8 de Francia, hizo un recorrido por el pensamiento de Frederich Nietzsche. Esta visita fue auspiciada por el Proyecto FONDECYT $\mathrm{N}^{\circ}$ 11160148 "Re-pensar el exilio: ampliaciones de sentido para un análisis filosófico en clave latinoamericana".

"Exilio y humanismo errante", fue la ponencia presentada en el mes de marzo por la Dra. Mariela Avila en I Coloquio Franco-Latinoamericano ¿Renacimiento de las Humanidades o Cenotafio del Humanismo? Las resistencias de las humanidades en el siglo XXI (Historia, Filosofía, Política, Cultura), organizado por la Universidad de Chile, la Universidad de Valparaíso, la Universidad Austral, la Universidad de Playa Ancha y la Universidad Católica Silva Henríquez.

En el mes de abril, la Dra. Mariela Avila participó del Coloquio Desplazamientos de la Filosofía en Chile, organizado por el Instituto de Filosofía y el Magíster en Pensamiento Contemporáneo de la Facultad de Filosofía y Humanidades de Valdivia. En esta ocasión su ponencia se tituló "La filosofía y el exilio, o la filosofía exiliada de la filosofía".

El día 22 de abril los estudiantes del ramo Filosofía Política de la Escuela de Filosofía, impartido por la Dra. Avila, tuvieron la visita de la Dra. Nora Strejilevich, quien dictó una clase sobre filosofía, memoria, testimonio y narración. Esta visita fue auspiciada por el Proyecto FONDECYT N 11160148 "Re-pensar el exilio: ampliaciones de sentido para un análisis filosófico en clave latinoamericana".

El 23 de abril la Dra. Mariela Avila organizó, en la Universidad Católica Silva Henríquez, el Conversatorio Violencias políticas y exilios. Una aproximación desde la narrativa del testimonio, con la presencia de la Dra. Claudia Gutiérrez, directora del Departamento de Filosofía de la 
Universidad de Chile, de la psicóloga Karen Bascuñán, Coordinadora Equipo de Educación del Sitio de Memoria Villa Grimaldi, y de la Dra. Nora Strejilevich, Profesora Emérita de la Universidad de San Diego, California. Esta actividad fue auspiciada por el Proyecto FONDECYT № 11160148 "Re-pensar el exilio: ampliaciones de sentido para un análisis filosófico en clave latinoamericana", del que la Dra. Avila es Investigadora Responsable.

La presentación del libro La experiencia del exilio y el exilio como experiencia de Ediciones UCSH, del que la Dra. Mariela Avila y el Dr. Braulio Rojas son compiladores, tuvo lugar en el mes de mayo en la Universidad Católica Silva Henríquez, y contó con la presencia de las Dras. Pamela Soto y Nora Strejilevich.

El día 14 de junio, los alumnos del ramo Filosofía Política, que imparte la Prof. Mariela Avila, realizaron una visita al Sitio de Memoria Parque por la Paz Villa Grimaldi. En esta ocasión contaron con el acompañamiento y la guía de la Prof. Camila Díaz, quien realizó su tesis de pregrado en este Sitio de Memoria.

En el mes de junio, la Dra. Mariela Avila participó del $V$ Congreso lberoamericano de Filosofía que se realizó en Ciudad de México. Allí fue parte del Simposio Exilio, destierro y diáspora, y presentó la ponencia "Exilio y escritura. La narración como un modo de reconstrucción subjetiva". También en junio, la Dra. Mariela Avila dictó el Workshop Repensar el exilio y sus violencias en Latinoamérica, en la Facultad de Filosofía y Letras de la Benemérita Universidad Autónoma de Puebla, en México.

En el mes de agosto se efectuó con los estudiantes de la carrera de Pedagogía en Filosofía, en el curso de Filosofía Chilena impartido por el Dr. Alex Ibarra, la actividad Qhapaq ñam, en la que, a través de una pedagogía del paisaje, se desarrolló un recorrido por el centro de la ciudad de Santiago. Esta experiencia buscó generar un acercamiento a las cosmovisiones y lenguas de los pueblos andinos en clave territorial.

El 25 de septiembre se realizó el Coloquio Nómade: Idea de la Filosofía de Jorge Millas, organizado por la Escuela de Filosofía en conjunto con 
distintas universidades chilenas, en donde se celebró el 50 aniversario de la publicación del libro Idea de la Filosofía. En esta oportunidad participaron el Dr. Rodrigo Pulgar de la Universidad de Concepción y el académico de nuestra escuela Dr. Nelson Rodríguez A.

El día 2 de octubre la Dra. Mariela Avila fue invitada como conferencista al Congreso de Estudiantes de Filosofía de la Universidad de Chile, donde presentó el trabajo "De exilios, descentramientos y narrativas. Un acercamiento filosófico a las prácticas exiliares del Cono Sur latinoamericano".

En el mes de octubre el académico Dr. Nelson Rodríguez de la Escuela de Filosofía, participó de la Semana de la Ciudadanía en el Colegio República de Siria de la Municipalidad de Ñuñoa. Su trabajo consistió en presentar una valorización de Jorge Millas y Luis Oyarzún, como fuentes filosóficas para pensar la ciudadanía en Chile.

El día jueves 10 de octubre, la Dra. Avila participó del panel Proceso editorial y publicación de artículos científicos: el oficio del sociólogo dentro de revistas de Ciencias Sociales, en el marco de la Semana de la Sociología de la UCSH.

\section{Becas}

El académico Pablo Solórzano, se adjudicó un Apoyo para la participación académica en Congresos Internacionales, concurso interno de la Dirección de Posgrado de la Universidad. Esto le permitirá participar en el $X$ Congreso Internacional sobre espiritualidad en la Sociedad, con la ponencia titulada "¿Quién y cómo se forma la élite política católica en Chile?" Este encuentro tendrá lugar entre el 29 de abril y el 1 de mayo del próximo año en la University British Columbia, en Vancouver, Canadá.

La Dra. Mariela Avila se adjudicó la beca de Estancias Cortas Postdoctorales, otorgada por la Fundación Carolina. La estancia de dos meses se llevará a cabo el primer semestre del próximo año en la Facultad de Filosofía de la Universidad de Salamanca, España, donde desarrollará 
el proyecto "Exilio y narración: cruces entre Hannah Arendt y María Zambrano".

\section{Publicaciones}

El académico Dr. Pablo Solórzano publicó el artículo "Una experiencia de asesoría en la instalación de los planes de formación ciudadana (Ley 20.911) en establecimientos de dependencia municipal de la Región Metropolitana de Chile", en Revista Foro Educacional, №32, 2019, pp. 53-66, en el primer semestre de 2019.

La académica Dra. Mariela Avila publicó el capítulo "L'exil dans le Cône Sud latino-américain. Le lieu de la demeure", en el libro Vers le desexil. Démarches, questions, savoirs, editado por Marie-Claire Caloz-Tschopp y Valeria Wagner. Este texto fue publicado por Editoriel L'Harmattan, en París, Francia, en 2019.

La académica Dra. Mariela Avila publicó el artículo "El exilio en el Cono Sur: acercamientos a un problema siempre vigente" En Hybris. Revista de Filosofía, de Cenaltes Ediciones, Vol. 10, Pp. 155-179, durante el segundo semestre de 2019. Esta publicación está indexada en WoS y ERIH Plus.

La académica Dra. Mariela Avila publicó el capítulo "Entre los posibles usos (y abusos) de Foucault: claves analíticas para pensar la tortura dictatorial en América Latina" en el libro Michel Foucault 30 años: Gubernamentalidad, Subjetivación y Escrituras de sí. Este libro fue editado por Luz María Lozano y Luis Lozano, y publicado Editorial Universidad del Atlántico, Puerto Colombia, en Colombia en 2019.

\section{Otras noticias}

En el mes de julio, los estudiantes de Pedagogía en Filosofía Gabriel Sepúlveda y Miguel Pinzón completaron el programa América Precolombina: Formación Docente en Interculturalidad que se realizó en el Museo Chileno de Arte Precolombino de Santiago de Chile. Esta activi- 
dad tiene como objetivo ampliar las perspectivas de enseñanza en los procesos formativos de estudiantes de pedagogía para el despliegue de la interculturalidad, mediante el desarrollo de la comprensión de la memoria y el patrimonio americano como bases teóricos-conceptuales. 